Journal Home Page:

http://perlinguam.journals.ac.za

\section{Per Linguam}

A Journal for Language Learning Tydskrif vir Taalaanleer

\title{
THE ROLES OF PHONOLOGICAL AWARENESS, RAPID AUTOMATISED NAMING AND MORPHOLOGICAL AWARENESS IN ISIXHOSA
}

Maxine Schaefer, University of South Africa.

Tracy Probert, Rhodes University.

Siân Rees, Rhodes University

\begin{abstract}
The current paper examines the unique contributions of phonological awareness (PA), rapid automatised naming (RAN) and morphological awareness (MA) to oral reading fluency (ORF) in isiXhosa. No published study has yet explored the individual contributions of these three cognitive-linguistic skills to reading in isiXhosa. Sixty-six grade 3 home language isiXhosa learners were assessed on these cognitive-linguistic skills. Results from a linear regression analysis showed that only RAN and MA, but not PA, were significant concurrent predictors of $O R F$. These results suggest that the role of $P A$ in reading in grade 3 learners in isiXhosa may have been overestimated because other important predictors of reading have not been controlled. Our data also suggest that grade 3 isiXhosa learners may make use of the morpheme as a grain size in reading. Our study highlights the need for longitudinal research which explores the roles of $P A, M A$ and RAN in reading development in order to inform reading pedagogy in isiXhosa and other Southern Bantu languages.
\end{abstract}

Keywords: phonological awareness, rapid automatised naming, morphological awareness, reading fluency, isiXhosa

\section{INTRODUCTION}

Increasing attention has been paid to literacy research in reaction to the poor literacy performance of South African children on international assessments of literacy (Howie et al., 2008; Howie et al., 2012; Howie et al., 2017). South Africa has a mother tongue education policy (Republic of South Africa, 1996). However, in practice, the majority of children receive instruction and learn in a Southern Bantu language ${ }^{1}$ in grades 1 to 3, with a switch to English instruction in grade 4 (Pretorius \& Spaull, 2016: 1450). While there are many reasons why literacy performance is low in South Africa and elsewhere, one of the reasons may be that there is little understanding of how literacy develops in the Southern Bantu languages (De Vos, Van der Merwe \& Van der Mescht, 2015: 21). Consequently, instructional practices may not best meet the needs of learners who must learn to read in a Southern Bantu language.

In response to this gap, there have been a number of large- and small-scale projects which have focused specifically on literacy in Southern Bantu languages (e.g., Northern Sotho: ${ }^{2}$ Wilsenach, 2013, 2019), and on how African language literacy transfers to English literacy given the role of 
English in education in some African countries (e.g., South Africa: Probert \& De Vos, 2016; Schaefer \& Kotze, 2019; Kenya: Kim \& Piper, 2019a; Malawi: Shin et al., 2015). Researchers have also been concerned about whether word reading theories developed for English are applicable to Southern Bantu language literacy (Kim \& Piper, 2019b: 327; Probert, 2016: 153; Probert \& De Vos, 2016: 4; Schroeder, 2013: 245; Trudell \& Schroeder, 2007: 166). Share (2008: 585) and Daniels and Share (2018: 101) echo this concern, explaining that since English is an 'outlier orthography', there has been an overreliance on what may be the case in English, with a disregard for languages which are phonologically, morphologically and orthographically different. Nevertheless, in a summary of the literature, Hulme and Snowling (2015: 6) report that, at least in alphabetically written languages, there is consensus on the cognitive predictors of word reading ability. These include phonological awareness (PA), rapid automatised naming (RAN, ${ }^{3}$ also called naming speed) and letter-sound correspondence knowledge. They also acknowledge the roles of vocabulary and morphological awareness (MA) in reading development, referring to them as 'higher level language skills' which may only be important once children have become more proficient in reading (Hulme \& Snowling, 2015: 4). The status of these cognitive-linguistic skills as predictors of reading in Southern Bantu languages, and specifically in isiXhosa, has been underexplored.

The current paper examines the contributions of PA, RAN and MA to oral reading fluency in isiXhosa, a transparently written Southern Bantu language from South Africa. No published study has yet explored the individual contributions of these three cognitive-linguistic skills to reading in isiXhosa. It therefore remains unknown as to whether research on English and other Indo-European languages is applicable to isiXhosa literacy development and reading pedagogy. This is important given that between $13 \%$ and $22 \%$ of children attend schools with isiXhosa as medium of instruction, depending on the grade (data from 2013 Annual National Assessments reported in Pretorius \& Spaull, 2016: 1450). In addition to this, given the literacy crisis in the country, there is a need for evidence-based research on the mechanisms underlying literacy development in isiXhosa.

While there is less research on learning to read in isiXhosa specifically, cross-linguistic research has revealed at least two universal principles which apply to all children gaining literacy. First, learning how to read is essentially learning how elements of one's spoken language correspond to elements of the written language (in the case of an alphabet, how phonemes map onto letters) (Verhoeven \& Perfetti, 2017: 4). Second, the process of reading and writing activates both phonological and morphological information, depending on the nature of the language and orthography (in the case of an alphabet, letter-to-sound conversion activates phonology) (Verhoeven \& Perfetti, 2017: 6). These two universals also highlight how aspects of the language and the way it is written can affect the development of reading skills. In our literature review, we therefore first review the structure of isiXhosa and how it is written. We then address the key constructs of the study (PA, RAN and MA) and what research in Southern Bantu languages reveals about these constructs. We then present our theoretical framework, the psycholinguistic grain size theory (PGST) (Ziegler \& Goswami, 2005), which informs our argument. 
M Schaefer, T Probert \& S Rees

\section{LITERATURE REVIEW}

\section{IsiXhosa language and orthographic structure}

IsiXhosa is a Southern Bantu language (Doke, 1954). It is one of the official languages spoken in South Africa and used as a medium of instruction in South African schools. IsiXhosa has the second largest number of first language (L1) speakers; it is spoken as L1 by $16 \%$ of the estimated 51 million people in the country (Statistics South Africa, 2012: 24).

IsiXhosa uses a transparent alphabetic writing system where the same sounds are consistently represented by the same letters or letter groups (De Vos et al., 2015: 4). The same 26 letters of the Roman alphabet are used in English, although some letters represent different sounds in each language. These letters and combinations of them are used to represent the five vowel ( Van der Merwe \& Le Roux, 2014: 3) and 52 consonant (Saul, 2013: 133) phonemes of isiXhosa. IsiXhosa has a limited number of consonant clusters mostly limited to loan words (e.g., in ikloko clock, [kl] is a consonant cluster) (Saul, 2013: 167), but has a number of complex graphemes. These are letter groups which consist of multiple letters representing a single phoneme (e.g. <hl> represents the voiceless lateral alveolar fricative $/ 1 /$ in hlala sit). IsiXhosa has a mostly simple syllable structure (generally open consonant-vowel syllables), although $/ \mathrm{m} /$ is allowed in the coda position (e.g., namhlanje today, /nam.ła.ndze/). Tone is used contrastively in isiXhosa, but is not represented in the orthography (Land, 2015: 64). These language and orthographic characteristics should result in rapid gains in reading accuracy and fluency once children have automated the letter-sound correspondences of the language.

IsiXhosa follows a subject-verb-object word order. It is an agglutinative language, and is characterised as having a rich morphological system, where affixes are prominent ( Gxilishe, Smouse, Xhalisa \& De Villiers, 2009: 47). All parts of speech can be inflected, but the verb is often the most complex, with nine available positions into which a grammatical morpheme might slot (Gxilishe et al., 2009: 47). Affixes can encode information about the subject and object of the sentence, as well as other grammatical information like tense and negation (Du Plessis, 1997; Gxilishe et al., 2009: 47), as illustrated in (1). The addition of affixes may also lead to phonological changes (such as vowel elision, vowel coalescence and consonantalisation) in the root and affixes (Nurse \& Phillipson, 2003: 8; Taljard \& Bosch, 2006: 433). Vowel coalescence is illustrated in (2).

(1) Abantwana abafundi

NC2-children neg-SM-LEARN-neg

'The children are not learning'

(2) Wenza umsebenzi (U+enza umsebenzi)

NC1-he/she SM-working

'He/she is working'

The consequence of these morphological characteristics is that the language is written conjunctively (Taljard \& Bosch, 2006: 433). That is, in writing, the affixes occur next to the verb root or noun with mostly no orthographic spaces between the verbal affixes and the verb root, or the nominal affixes and noun root. As a result, words are usually longer than those found in Per Linguam 2020 36(1):90-111 
English and a single word may even represent a whole sentence. For example, Ndiyabathanda (I love them) is orthographically one word, but it is made up of several smaller morphemes ndi-ya$b a-t h a n d-a$. It has been noted that this kind of information density in words can work against a reader, even in a transparent orthography (Yan, Tian, Bai \& Rayner, 2006: 267).

In summary, the phonological structure of isiXhosa and the transparent writing system should lead to the rapid acquisition of phoneme awareness and decoding skills. On the other hand, the complex morphological characteristics of the language and the long multisyllabic orthographic words may pose challenges for readers.

\section{Phonological awareness, rapid automatised naming, morphological awareness and reading}

Phonological awareness (PA) is an 'umbrella term' which refers to the awareness of and ability to manipulate the sounds of one's language ( Anthony, Lonigan, Driscoll, Phillips \& Burgess, 2003: 473). This includes sensitivity to different units of sound, such as the word, syllable, onset, rime and phoneme (Anthony et al., 2003: 473; Wilsenach, 2013: 18). Syllable awareness refers to the ability to segment a word into its constituent syllables, e.g., butterfly can be segmented into three syllables: bu-ter-fly. Phoneme awareness refers to a sensitivity to the smallest unit of sound, the phoneme, e.g., fly consists of three phonemes: $f-l-y$.

Research has converged to find that PA is an underlying cognitive-linguistic skill important for reading in all languages (Hulme \& Snowling, 2015: 6). However, the strength of its relationship to reading may vary by orthographic transparency in alphabetic orthographies (Landerl et al., 2019: 229; Moll et al., 2014: 74; Vaessen et al., 2010: 837; Ziegler et al., 2010: 556) or the writing system (Ruan, Georgiou, Song, Li \& Shu, 2018: 190). The contribution of PA to reading also changes over time or with grade level and depending on the level of PA (i.e., word, syllable or phoneme). Generally, PA's contribution to reading accuracy (proportion of correctly read words, usually in untimed conditions) and reading fluency (correct words read per minute) decreases over time as children become more automatic and proficient in their reading (Landerl et al., 2019: 228; Vaessen et al., 2010: 837). There is a reciprocal relationship between PA and decoding (Goswami \& Bryant, 2016; Hulme \& Snowling, 2015: 3), with training on PA leading to improvements in both PA and decoding (Suggate, 2016: 86).

RAN is the ability to name out loud highly familiar stimuli (colours, objects, numbers or letters) in a given time (Kirby, Georgiou, Martinussen \& Parrila, 2010: 341; Norton \& Wolf, 2012: 429). There is considerable research outlining the importance of RAN for reading, but there is a debate as to what RAN tasks measure. This debate is beyond the scope of this paper. ${ }^{4}$ RAN is a significant independent predictor of reading fluency in a number of languages written alphabetically, with varying degrees of transparency (e.g., English: Swanson, Trainin, Necoecha \& Hammill, 2003: 428; French: Desrochers, Manolitsis, Gaudreau, \& Georgiou, 2018: 1710; Greek: Georgiou, Parrila \& Papadopoulos, 2016a: 1807; Spanish and Czech: Caravolas, Lervåg, Defior, Málkova \& Hulme, 2013: 1405; Arabic: Tibi \& Kirby, 2018: 78; Northern Sotho: Makaure, 2016: 136), as well as in non-alphabetically written languages (e.g., Chinese: Georgiou, Aro, Liao \& Parrila, 2016b: 57; Japanese Hiragana and Kanji: Inoue, Georgiou, Muroya, Maekawa \& Parrila, 2017: 1350). A recent meta-analysis of 137 studies found that RAN has a stronger relationship with reading fluency than reading accuracy and that this relationship to 
fluency remains stable through the different grade levels (Araújo, Reis, Petersson \& Faísca., 2015: 877). In contrast, its contribution to reading accuracy decreases over time (Araújo et al., 2015: 879). Araújo et al. (2015: 874) reported a significant moderate to strong correlation between RAN and word reading fluency $(\mathrm{r}=0.45,95 \%$ CI $0.43 ; 0.47)$ and text reading fluency $(\mathrm{r}$ $=0.45,95 \%$ CI $0.38 ; 0.50)$ in alphabetic languages. An earlier meta-analysis also reported a moderate correlation between RAN and word reading (Swanson et al., 2003: 429). Stronger associations have been reported between reading and alphanumeric RAN tasks (numbers: $\mathrm{r}=$ 0.48; letters: $r=0.51$ ) than non-alphanumeric tasks (colours: $r=0.33$; objects: $r=0.35$ ) (Araújo et al., 2015: 877). Although RAN is an important predictor of reading fluency, it is not yet clear whether interventions can improve RAN, or whether reading fluency and RAN are reciprocally related. Available evidence from intervention studies is mixed. Some authors have reported faster naming speed after a RAN intervention (French: RAN objects, Vander Stappen \& Van Reybroeck, 2018: 12), but others found no significant effect on naming speed (RAN letters: Dutch, de Jong \& Vrielink, 2004: 65; and English, Fugate, 1997: 182). With respect to a reciprocal relationship between naming speed and reading fluency, Vander Stappen and Van Reybroeck (2018: 12) report that their RAN intervention improved the reading fluency of participants in French, and Wolff's (2014: 151) reading intervention improved the naming speed of learners in Swedish. On the other hand, longitudinal data from Chinese revealed that RAN predicted later reading fluency, but reading fluency did not predict later RAN (Georgiou, Wei, Inoue \& Deng, 2020: 8). The conflicting findings here make it difficult to determine the pedagogical implications of naming speed results, but the consistent finding that RAN is implicated in reading fluency development warrants its inclusion in studies on reading acquisition.

MA refers to the ability to access, reflect upon and consciously manipulate morphemes and the morphological structure and meaning of words (Carlisle, 2003: 295; McBride-Chang et al., 2005: 417). Morphemes are the smaller units within words that provide clues about meaning, spelling and pronunciation (Carlisle, 2003: 295; Kirby et al., 2012). MA usually uniquely explains 2-10\% of variance found in a range of reading measures, including spelling, single word reading accuracy, decoding of morphologically complex words, word recognition, vocabulary development (directly and indirectly), and reading comprehension (Acha, Laka \& Perea, 2010; Deacon, Kirby \& Casselman-Bell, 2009; Kirby et al., 2012; McBride-Chang et al., 2008; SaieghHaddad \& Geva, 2007; Wolter, Wood, \& D’zatko, 2009; Zhang \& Koda, 2012).

The relationship between MA and reading comprehension has received the most attention in MA literature. This is because morphemes are meaning units. Research on MA and comprehension converges that MA aids the comprehension of words (Kuo \& Anderson, 2006: 177; Zhang \& Koda, 2012: 1197; Goswami \& Ziegler, 2006). The relationship between MA and the decoding of words, and by extension, how MA contributes to fluent reading (Goswami \& Ziegler, 2006: 451), has received less attention. Manolitsis et al. (2019: 26-28) found a reciprocal relationship between MA and word reading fluency in English, but not in Greek. Other studies have provided evidence of a significant relationship between MA and reading fluency: in a transparent language such as Spanish (D'Alessio, Jaichenco \& Wilson, 2018: 1081), a morphologically complex language like Arabic (Saiegh-Haddad \& Geva, 2007: 499), and an agglutinating language like Finnish (Bertram, Laine \& Virkkala, 2000: 294). Reviews of MA intervention studies indicate that MA interventions can improve MA, as well as reading outcomes (operationalised as word 
reading accuracy and fluency, and comprehension), with the greatest facilitative effect for poorer readers (Bowers, Kirby \& Deacon, 2010: 144; Reed, 2008: 46). Bowers et al. (2010: 169) suggest that MA instruction boosts lexical quality, thereby 'increasing [the] efficiency of word identification'. Additionally, they argue that MA interventions encourage readers to focus on meaning, which fosters the comprehension of more complex words, especially when texts get more challenging as (reading) age increases. Finally, MA instruction allows poor readers, who may have phonological processing deficits, to develop alternate word identification strategies (Bowers et al., 2010: 173).

MA is influenced by the phonology and orthography of a language to some extent. Regardless of a morpheme's inflectional or derivational status, speakers fare better with items that can be solved phonetically (e.g., help: helpful) than those that are less morphologically transparent due to a phonetic or orthographic shift (e.g., sign: signal) (Kirby et al., 2012: 392; Pike, 2011: 13). Affixes that cause phonological or orthographic shifts, or a change in meaning of the original word pose difficulties to the reading or spelling of derived words as the inflected or derived words cannot always be matched one-to-one to the word in the reader's oral vocabulary. IsiXhosa morphemes attached to noun and verb roots constantly influence the sound, look and meaning of roots, which might complicate the reading process despite the transparency of the orthography.

\section{Phonological awareness, rapid automatised naming, and morphological awareness in Southern Bantu languages}

Cross-sectional studies of PA in Southern Bantu languages (i.e., isiXhosa, isiZulu, Siswati, Sesotho sa Leboa ${ }^{5}$, Setswana and Herero) have produced conflicting findings regarding the role of syllable and phoneme awareness for reading fluency and reading accuracy at different grade levels. Studies which have included measures of PA differ by: (1) whether syllable, phoneme awareness or composite scores were used, (2) how reading was measured (word or text reading; accuracy or fluency), and (3) what other variables were controlled in the regression. The review of the PA literature reveals that syllable and phoneme awareness may significantly predict reading accuracy and fluency when other variables (such as vocabulary) are not controlled, although the trend is not consistent across studies or languages.

At grade 3 level, it is unclear whether different levels of PA are predictive of reading accuracy and reading fluency. Syllable awareness predicted word reading accuracy $\left(\mathrm{R}^{2}=27.4 \%\right)$, but not fluent reading, in Northern Sotho speaking children when phoneme awareness was not measured (Wilsenach, 2013: 25). In another study of Northern Sotho grade 3 learners, only phoneme deletion, and not phoneme isolation or syllable deletion, was a significant predictor of word reading accuracy and text reading fluency (Wilsenach, 2019: 7). In contrast, Malda, Nel and Van de Vijver (2014: 42) reported a non-significant estimate of phoneme awareness to word and text reading fluency for grade 3 Setswana readers after controlling for vocabulary. Probert (2019: 8) found that only syllable awareness, not phoneme awareness, significantly predicted oral reading fluency (measured in characters read correctly per minute) in both isiXhosa and Setswana after controlling for MA. Unlike other studies, Probert (2019: 5) scored the PA tasks on an ordinal scale allowing for partially correct answers. It is uncertain how this difference in scoring may have affected results. Finally, Diemer (2016: 145), who combined the scores for syllable and phoneme deletion into a PA score, found that PA explained significant variance in oral reading 
fluency after controlling for RAN $\left(\mathrm{R}^{2}=18 \%\right)$. However, when splitting the sample into good PA and poor PA groups, PA was no longer significant for the good PA group. Finally, studies which explored other grades reported significant contributions of PA to reading. First language (isiZulu and Siswati) phoneme awareness measured at the start of grade 1 was a significant predictor of isiZulu and Siswati word reading fluency at the end of grade 1 after controlling for various preliteracy skills (Schaefer \& Kotzé, 2019: 9). Veii and Everatt (2005: 248) reported that phoneme awareness explained $15 \%$ of the variance in word reading accuracy, after controlling for grade, RAN and phonological working memory in grade 2 to 5 Herero readers.

The RAN-reading relationship in Southern Bantu languages has been less researched. The RANreading relationship has been explored in Herero and Northern Sotho through the use of nonalphanumeric RAN stimuli, and in isiXhosa using a RAN digits test. RAN significantly predicted word reading accuracy in Herero, accounting for $2 \%$ of variance in word accuracy after controlling for PA, grade, sex, school and age (Veii \& Everatt, 2005: 248), but was not a significant predictor of word reading accuracy in Northern Sotho (Makaure, 2016: 136). Data from isiXhosa indicate a large significant contribution $\left(\mathrm{R}^{2}=42 \%\right)$ of RAN to reading fluency for a group of grade 3 readers with poor PA but not for a group with better PA, and no significant contribution to text reading accuracy for either group after controlling for PA (Diemer, 2016: 145). It is unclear whether the very large contribution of RAN to reading fluency in isiXhosa is a result of the alphanumeric RAN task, or the grouping of participants by PA ability, or whether the trend results from the conjunctive writing system.

The information on MA, specifically, in Southern Bantu languages comes from only two studies of isiXhosa readers: Rees (2016) and Probert (2016, 2019). Rees (2016) and Probert $(2016,2019)$ assessed some of the same learners, and some of the data from these two studies are reanalysed in the current paper. Rees (2016: 98) found that MA (measured by a sentence/word analogy task, an adapted wugs task, a word-building task and a morpheme identification task) had a strong significant correlation with oral reading fluency $(\mathrm{r}(74)=0.61)$, and a significant moderate correlation with reading comprehension $(\mathrm{r}(74)=0.33)$ in a sample of grade 3 readers. The participants in this sample, however, had very low comprehension levels. Rees (2016: 116) suggests that the number of morphemes participants can read correctly per minute in isiXhosa is related to how well they can identify and manipulate morphemes in MA tasks. The crosssectional design of the research means that the direction of causality cannot be determined. Furthermore, Rees (2016) did not use regression analysis to determine the unique contribution of each MA task to reading fluency and comprehension. Probert (2019) examined the contribution of MA to reading fluency in isiXhosa and Setswana, controlling for PA. Probert (2019: 8) found that MA was not a significant predictor of ORF (measured as characters read correctly per minute) in isiXhosa or Setswana after controlling for PA. While there was a good distribution in the MA scores, the tasks (wugs and morpheme identification) had very low reliability (Cronbach's $\alpha=0.44$ ) (Probert, 2019: 8). The role of MA in reading in the Southern Bantu languages remains uncertain. There is therefore a need to better understand the involvement of this cognitive-linguistic skill in reading given the complex morphology of the language. 
M Schaefer, T Probert \& S Rees

\section{THEORETICAL FRAMEWORK}

\section{Psycholinguistic grain size theory}

The PGST (Ziegler \& Goswami, 2005; Ziegler et al., 2001) was used to interpret our results. The PGST (Ziegler \& Goswami, 2005; Ziegler et al., 2001) seeks to explain the cross-linguistic differences in rate of reading acquisition as a result of differences in the rate of PA development and orthographic consistency. The PGST proposes that learning to read involves finding the shared mappings between the available sounds of a language (availability) and the way those sounds are most consistently represented orthographically (granularity) (Ziegler \& Goswami, 2005: 3). Languages differ in the phonological units which are salient in the spoken language, and the phonology-orthography correspondences which are salient in the written language. For example, the phonological structure of Southern Bantu languages, such as isiXhosa and Northern Sotho, privileges syllable awareness (Diemer, Van der Merwe \& De Vos, 2015: 334; Wilsenach, 2019: 7), but the alphabetic orthography with which they are written privileges the phonemes represented by letters. The graphemes of orthographies represent different phonological or morphemic units. For example, the kana of the Hiragana writing system for Japanese represents syllables (Inoue et al., 2017: 1337), the aksharas of Brahmi-derived scripts represent both syllables and phonemes (Nakamura, Joshi \& Ji, 2018: 499-500; Share \& Daniels, 2016: 18), and the characters of the Chinese writing system primarily represent morphemes, with a phonetic radical (Luo et al., 2018: 336). Through practice and targeted instruction, the beginner reader finds the most consistent mappings (grains) between the orthography and phonology. These grains can be small (phoneme-letter correspondence) or large (syllable-letter group), and readers theoretically employ different grain sizes depending on the language read, their reading proficiency and task demands.

A limitation of the PGST is that it does not address the role of morphology in literacy acquisition (Goswami \& Ziegler, 2006: 451). Durgonoğlu (2006: 438) highlights that the relationship between morphological and phonological knowledge needs to be better understood, citing evidence from Turkish that morphological processes at the end of roots affect PA and therefore literacy acquisition. Indeed, evidence from isiXhosa also suggests that verbal morphology affects the awareness of phonological units in different parts of a word (Diemer et al., 2015: 337).

There is evidence that Southern Bantu language readers use the morpheme as a grain size in reading. Probert (2019) explored the preference in grain size of isiXhosa and Setswana grade 3 learners while reading connected text, paying particular attention to the use of the syllable and morpheme. Results showed the syllable to be the dominant grain size unit used in connected-text reading in both languages. However, the isiXhosa readers also showed a sensitivity to the use of the morpheme as a grain size in connected-text reading. According to Probert (2019: 9), this could be partially due to the conjunctive nature of isiXhosa, as isiXhosa learners need to know where the morphological segments are when decoding sentences due to the multimorphemic nature of words in isiXhosa. Eye-movement data of isiZulu readers also suggest that adult readers attend to morphemes when reading morphologically complex words (Land, 2016: 8). We therefore drew upon a revised version of the PGST (Probert, 2016: 146) which explicitly addresses the role of MA in reading, which was used to interpret our data. The revised PGST model (Figure 1) accounts for the granularity of the morpheme as an optional grain size in the 
orthography, and also adds morphology under availability. The morpheme is represented vertically as opposed to horizontally to illustrate that morphemes can range from one letter or sound to multiple letters or sounds to a whole word.

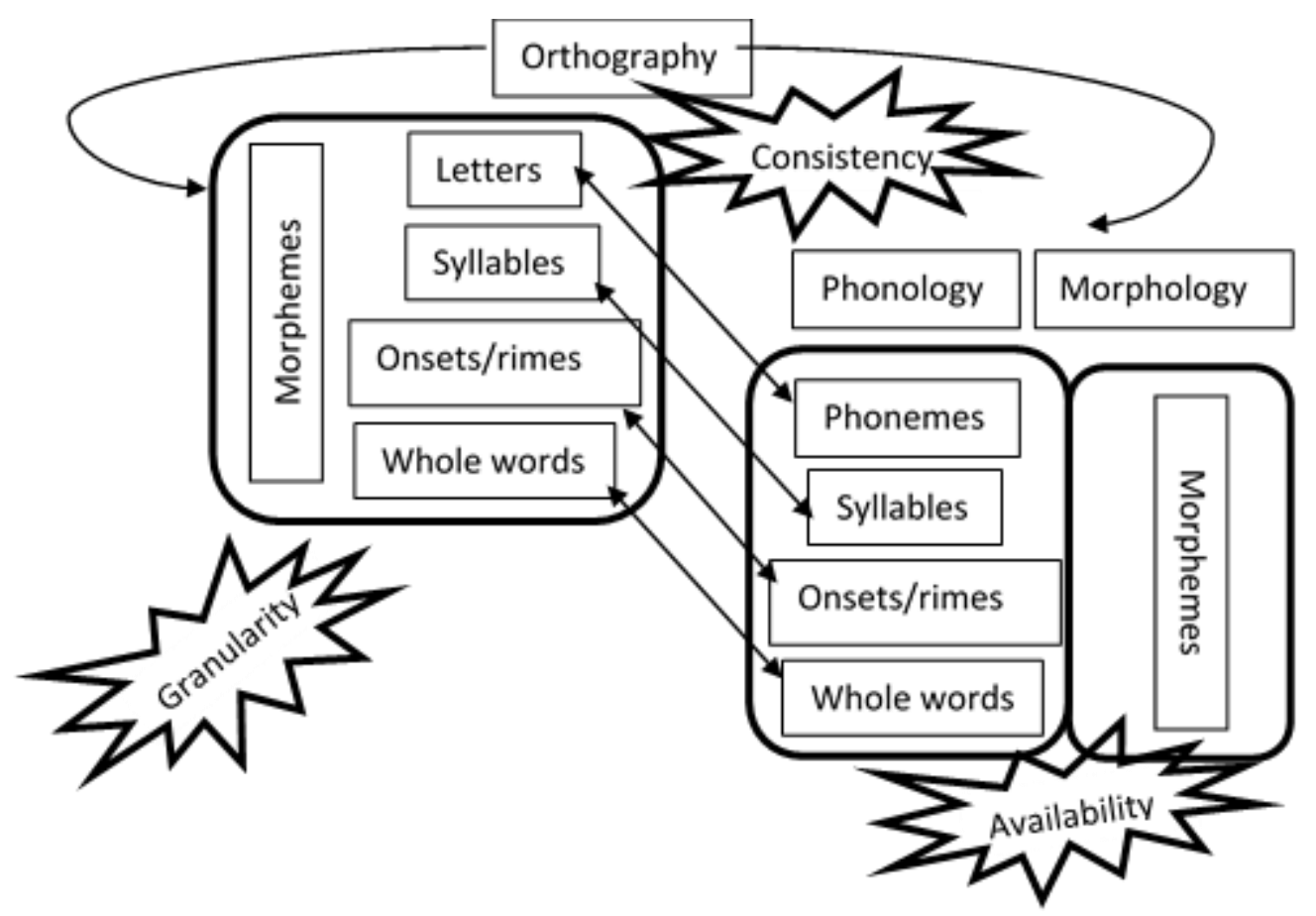

Figure 1: Schematic depiction of the revised psycholinguistic grain size theory

Source: Probert (2016: 146)

\section{The present study}

In an attempt to better understand the contribution of PA, RAN and MA to reading in isiXhosa, we measured the syllable awareness, phoneme awareness, RAN, MA and oral text reading fluency (ORF) of grade 3 isiXhosa readers using a cross-sectional research design. These skills were initially assessed as part of three individual postgraduate studies reported in Diemer (2016), Probert $(2016,2019)$ and Rees (2016), who assessed many of the same isiXhosa participants. The research databases of the authors were merged for the current study.

The following research questions guided this paper:

1. What is the unique contribution of syllable awareness, phoneme awareness, RAN and MA to the oral reading fluency of grade 3 isiXhosa speakers?

2. Do the findings support the revised PGST? 
M Schaefer, T Probert \& S Rees

\section{METHOD}

\section{Participants and school context}

Seventy-four participants were successfully linked from the three databases. Eight participants were excluded, with the remaining 66 participants included in the present study (see Preliminary analysis). Participants (36 girls, 30 boys) were on average 9 years 9 months old $(S D=8.5$ months). Participants were drawn from three no-fee schools with isiXhosa as medium of instruction. These schools were situated in two peri-urban communities situated close to two small coastal towns in the Eastern Cape, South Africa. The authors acknowledge that variables such as non-verbal intelligence, home background factors and vocabulary should be controlled in future studies. Consent to participate in the study was provided by the school, teachers and parents, and the grade 3 learners provided verbal assent to participate.

\section{Measures}

There are no standardised tests to assess cognitive-linguistic skills or reading in isiXhosa and other Southern Bantu languages. For this reason, language-appropriate research instruments were developed for this study.

\section{Phonological awareness}

PA was measured using pseudoword deletion tasks which targeted syllables and phonemes. ${ }^{6}$ Pseudowords were devised by combining allowable isiXhosa syllables into three-syllable pseudowords, which were checked by an L1 isiXhosa speaker to confirm their pseudoword status. Pseudowords were selected as stimuli, as Malda et al. (2014: 37) argue that PA tasks with pseudoword stimuli provide more accurate measures of PA as they are not affected by the properties of real words (i.e., word class, semantics and/or frequency of occurrence). The deletion tasks required participants to produce a three-syllable pseudoword without the target syllable (first, middle or final syllable position) (e.g. say setika without /se/), or target phoneme (word initial only) (e.g. say logeka without /1/). An initial phoneme deletion task was used, given the open syllable structure of isiXhosa and the small number of words with consonant clusters, which makes it difficult to delete phonemes from other parts of the word (Diemer et al., 2015: 70). The tasks were preceded by instructions and two practice items where participants received corrective feedback. Thereafter, 10 pseudowords were presented without feedback. Scores were converted to a percentage correct score. The reliability of these tasks was acceptable for both the syllable (Cronbach's $\alpha=0.81$ ) and phoneme levels (Cronbach's $\alpha=0.93$ ).

\section{Rapid automatised naming}

RAN was measured using an adapted RAN digit task (Compton, Olson, Defries \& Pennington, 2002: 349). Participants were required to name numbers $(2,4,7,6,9)$ in isiXhosa that were presented serially semi-randomly in an array of five numbers per row (15 rows) for 15 seconds. This adapted RAN task was used due to time constraints. Participants first practised before the administration of the task by identifying the numbers in isolation and then by completing a practice digit array before completing the experimental array. Participants' errors were subtracted 
from the total number of stimuli named in the experimental array. The number of items correctly named was then divided by 15 to give an items correct per second score.

\section{Morphological awareness}

MA was measured with a word and sentence analogy task (Nunes, Bryant \& Bindman, 2006: 773) adapted for isiXhosa ${ }^{7}$ which assessed both inflectional and derivational morphology. The analogy task is able to capture 'the broad construct that is MA' (Kirby et al., 2012: 392) and examine all the grammatical categories in a language, for example, the knowledge of the function of, as well as the manipulation of, morphological affixes, such as tense, aspect, noun classes and negation. Across languages, there is a general trend to research the awareness of derivational morphemes as they are inherently more complex than inflectional morphemes, because of the change in grammatical categories (Zhang \& Koda, 2013). However, in isiXhosa, inflectional morphology can be comparably as hard because, though the grammatical category of the word remains constant, the inflectional morphemes on roots give rise to the long, multimorphemic words in the language, for example, Andisabaleki (I am not running).

Participants were orally presented with an example of an inflectional or derivational process in an isiXhosa word or sentence and were then asked to complete that process on a new word or sentence (e.g., isiXhosa: ukulwa: umlwi :: ukupheka: (umpheki); English: to fight: fighter :: to sing: (singer)). Participants completed three practice items with corrective feedback. Thereafter, participants completed 10 experimental items without feedback. Half the items tested inflectional morphology and half tested derivational morphology. A prefix and suffix correctness distinction was also made when scoring the test, which formed part of a larger prefix and suffix composite score in the original study (Rees, 2016: 82), to see whether the specific placement of the morpheme affected how easily it was manipulated. The total test was therefore scored out of 25 . The task had acceptable reliability (Cronbach's $\alpha=0.83$ ).

\section{Oral reading fluency}

Reading ability was measured using a one-minute oral reading fluency task, as used in the Early Grade Reading Assessments (Dubeck \& Gove, 2015: 318) and in other studies in South Africa (Kotze, Fleisch \& Taylor, 2019: 207; Spaull, Pretorius \& Mohohlwane, 2020: 8). A grade 3 equivalent text was presented to learners. They were asked to read the text aloud as best they could. The text was 112 words long, with an average of 8.6 words per sentence and 6.7 letters per orthographic word. Errors were recorded and subtracted from the total number of words attempted in one minute to give the orthographic words correct per minute score.

\section{Data collection procedure}

Participants were randomly selected from the grade 3 classes (two classes per school) in each school. Learners were assessed individually in the only available unoccupied room in each school in two sessions of 30 minutes. In some cases, the venue was a staff room (no staff were present) or an unused computer room. Testing took place between August and October (terms 3 and 4 of the academic year). Each task was administered in isiXhosa by trained undergraduate and postgraduate students. The order of tasks was counterbalanced across participants. There was a minimum of one day and a maximum of one week between testing sessions for each participant. 
The tasks were audio recorded and scored on paper by the enumerators. All the paper scores were checked by the researchers and coded for data analysis.

\section{Data analysis procedure}

The linked dataset of 74 participants was checked for missing data and outliers. Eight of the original participants were removed from the analysis (four with missing data and four who were aged 12 years or older) resulting in 66 participants. ${ }^{8}$ The descriptive statistics of and correlation among variables was calculated. A linear regression analysis was run to determine the contribution of PA, RAN and MA to reading fluency. The data were analysed using IBM SPSS version 25 (IBM Corp, 2017).

\section{RESULTS}

Descriptive statistics and bivariate correlations are presented in Table 1. The syllable deletion, MA and RAN data were normally distributed. Phoneme deletion had a platykurtic distribution with positive skew, while the ORF scores were also positively skewed. Transformation of the data did not improve normality, so the raw scores were used in the linear regression analysis.

On average, learners performed significantly better on the syllable deletion $(M=52.59, S E=$ 3.68) than on the phoneme deletion tasks $(M=39.66, S E=4.46), t(65)=3.55, p=0.001$. This difference represents a small to medium effect $(d=0.44)$. For the syllable deletion and phoneme deletion tasks, $6.10 \%$ and $25.80 \%$ of learners scored zero, respectively, indicating that a proportion of learners struggled considerably with PA. The learners had a range of reading abilities, and $16.7 \%$ of learners were unable to read a single word in the oral reading fluency test while $10.6 \%$ were able to read 40 or more words correctly per minute. Table 1 also shows that the variables had a weak to moderate linear relationship with each other, $r(64)=0.364-0.485, p$ $<0.01$. The two phonological awareness tasks were strongly correlated, $r(64)=0.627, p<0.001$.

Table 1: Descriptive statistics and zero-order bivariate correlations of variables

\begin{tabular}{|l|l|l|l|l|l|l|l|l|l|}
\hline & \multicolumn{5}{|c|}{ Descriptive statistics } & \multicolumn{3}{c|}{ Zero order bivariate correlations } \\
\hline Variable & $\begin{array}{l}\text { Mean } \\
\text { (SE) }\end{array}$ & SD & $\begin{array}{l}\% \text { zero } \\
\text { scores }\end{array}$ & Skew & Kurt & Syl. del. & $\begin{array}{l}\text { Phon. } \\
\text { del. }\end{array}$ & RAN & MA \\
\hline $\begin{array}{l}\text { Syllable } \\
\text { deletion (\%) }\end{array}$ & $\begin{array}{l}52.59 \\
(3.68)\end{array}$ & 29.91 & 6.10 & -0.15 & -1.16 & & & & \\
\hline $\begin{array}{l}\text { Phoneme } \\
\text { deletion (\%) }\end{array}$ & $\begin{array}{l}39.66 \\
(4.46)\end{array}$ & 37.04 & 25.80 & 0.32 & -1.55 & $0.627^{* * *}$ & & & \\
\hline $\begin{array}{l}\text { RAN } \\
\text { (items/second) }\end{array}$ & $\begin{array}{l}0.677 \\
(0.04)\end{array}$ & 0.36 & 0.00 & 0.52 & 0.08 & $0.433^{* * *}$ & $0.419^{* * *}$ & & \\
\hline MA (total) & $\begin{array}{l}9.62 \\
(0.58)\end{array}$ & 4.75 & 0.00 & 0.32 & -0.07 & $0.378^{* *}$ & $0.443^{* * *}$ & $0.364^{* *}$ & \\
\hline ORF (wcpm) & $\begin{array}{l}17.70 \\
(1.61)\end{array}$ & 13.12 & 16.70 & 0.27 & -0.75 & $0.396^{* *}$ & $0.450^{* * *}$ & $0.478^{* * *}$ & $0.485^{* * *}$ \\
\hline
\end{tabular}

Note: $* \mathrm{p}<.05 * * \mathrm{p}<.01 * * * \mathrm{p}<.001$

wcpm = words correct per minute; $\mathrm{SE}=$ standard error; $\mathrm{SD}=$ standard deviation; Skew = skewness; Kurt = kurtosis; Syl. del. = syllable deletion; Phon. del. $=$ phoneme deletion; RAN $=$ rapid automatised naming; $\mathrm{MA}=$ morphological awareness

Source: authors' own work 


\section{Regression results}

A multiple linear regression analysis was run with RAN, PA and MA as the predictor variables and ORF as the outcome variable. These results are reported in Table 2 . The model accounted for a significant $37.2 \%$ (adjusted $\mathrm{R}^{2}=33 \%$ ) of the variance in $\mathrm{ORF}, F(4,61)=9.017, p<0.001$. The $95 \%$ confidence intervals for both syllable $(95 \%$ CI $[-0.091 ; 0.146])$, and phoneme deletion (95\% CI [-0.038; 0.157]) overlapped with zero, confirming that these two variables were not significant predictors of ORF in this sample. In contrast, both RAN and MA were significant predictors of ORF, with comparable standardised beta coefficients ( RAN $\beta=0.276$; MA $\beta=$ $0.287)$.

Table 2: Summary of multiple regression with ORF as dependent variable and syllable deletion, phoneme deletion, RAN and MA as predictors

\begin{tabular}{|l|c|c|c|c|c|}
\hline Predictors & & \multicolumn{4}{|c|}{ Oral reading fluency } \\
\hline & $B$ & $S E$ & $\beta$ & $t$ & $p$ \\
\hline (Constant) & -0.462 & 3.627 & & & 0.899 \\
\hline Syllable deletion & 0.028 & 0.059 & 0.063 & 0.466 & 0.643 \\
\hline Phoneme deletion & 0.059 & 0.049 & 0.168 & 1.219 & 0.227 \\
\hline RAN & 9.931 & 4.223 & 0.276 & 2.352 & 0.022 \\
\hline MA & 0.793 & 0.322 & 0.287 & 2.462 & 0.017 \\
\hline
\end{tabular}

Note: $\mathrm{R}^{2}=0.372$, adjusted $\mathrm{R}^{2}=0.33$

Source: authors' own work

\section{DISCUSSION}

The purpose of our study was to determine the unique concurrent contribution of three cognitivelinguistic skills to the oral reading fluency of grade 3 isiXhosa readers. These cognitive-linguistic skills included PA (measured at the syllable and phoneme level), RAN (measured by a digit naming task) and MA (measured by a word and sentence analogy task). We used a crosssectional research design to describe these concurrent relationships with ORF.

Knowledge of how these cognitive-linguistic skills contribute to reading fluency can shed light on the types of skills which should be addressed in teaching programmes. For example, there is a debate in Southern Bantu language reading pedagogy about whether or not the teaching of phoneme awareness is necessary. Some scholars argue that it is not necessary, given that these languages are written transparently and the syllable is a salient unit available for reading (Schroeder, 2013: 258). Others argue that, because of the alphabetic writing system, there is a need for systematic phonics instruction which makes the correspondence between letters and phonemes explicit (Spaull et al., 2020: 12; Wilsenach, 2019: 9). Evaluating this debate is complicated because PA can be measured at different levels (i.e., word, syllable, onset-rime and phoneme) and with tasks of various difficulty (e.g., blending, isolation, deletion and soundmatching tasks). Furthermore, the relationship between PA and reading abilities changes across grade levels and with reading proficiency. The roles of MA and RAN in Southern Bantu language reading have so far been underexplored and therefore have not been explicitly addressed in instructional programmes. 


\section{Schaefer, T Probert \& S Rees}

Results from the regression analysis showed that PA, RAN and MA accounted for 33\% (adjusted $\mathrm{R}^{2}$ ) of the variance in ORF. Our model showed that syllable deletion and phoneme deletion were not significant concurrent predictors of ORF after controlling for RAN and MA. On the other hand, RAN and MA each made unique contributions to ORF after controlling for PA. The standardised regression coefficients indicated that MA $(\beta=0.287)$ and $\operatorname{RAN}(\beta=0.276)$ were equally good predictors of ORF in this sample.

Our results support evidence from other transparent orthographies that PA ceases to be a predictor of ORF in the later grades after controlling for other cognitive-linguistic skills (e.g., Malda et al., 2014: 42). In transparent orthographies, readers develop phonological recoding skills quickly because of the consistency of letter-sound mappings (Ziegler \& Goswami, 2005: 11). PA therefore becomes automated quickly, and its predictive power is reduced in the later grades. Our data do not necessarily support this reason as a number of children in our sample had underdeveloped PA and reading abilities, a trend also reported by Wilsenach (2019: 7) for Northern Sotho. Rather, we suggest that the lack of predictive power of PA for ORF in our study was a result of the importance of other skills, namely RAN and MA, which are also implicated in ORF. More research across grade levels, and the use of different PA task types such as isolation and blending tasks, is needed to flesh out the relative importance of each level of PA to various literacy skills.

RAN has been implicated in reading fluency in a number of languages and writing systems (Araújo et al., 2015: 877). While there is a debate as to what RAN measures, our data highlight its importance for fluent reading even in the conjunctively written morphologically complex isiXhosa. The greater variance explained by RAN in our sample, compared to Northern Sotho (Makaure, 2016: 136) or Herero (Veii and Everatt, 2005: 248) readers, may be due to our use of a digit RAN task. Alphanumeric RAN tasks are often better predictors of reading than nonalphanumeric RAN tasks (Araújo et al., 2015: 877). More research is needed to better understand how different measures of RAN are related to reading fluency in Southern Bantu languages.

The role of MA for reading in Southern Bantu languages is underexplored. In our sample, MA was as good a predictor of ORF as RAN in isiXhosa. While MA has typically been explored for its importance in reading comprehension, our results suggest that readers rely on their awareness of morphemes to process connected text in isiXhosa. This finding supports that of Probert (2019), who showed that isiXhosa learners used the morphemes as a secondary grain in decoding, as well as that of Land (2016: 8), who highlighted the use of morphemes for reading multisyllabic words by isiZulu adult readers. Our data provide further evidence for the role of morphological processing in early grade fluent reading in agglutinating languages (Bertram et al., 2000). We argue that the agglutinating nature of isiXhosa, rather than its orthographic transparency, is responsible for the significant relationship between MA and reading fluency. For example, MA was not a significant predictor of ORF in transparently written Greek after controlling for PA and RAN (Desrochers et al., 2018: 1710) or vocabulary and RAN (Manolitsis, Grigorakis \& Georgiou, 2017: 9). Desrochers et al. (2018: 1713) argue that the lack of contribution of MA to reading fluency in Greek is because phoneme-grapheme recoding is so automatic and efficient in Greek that children do not need to rely on alternate reading strategies. Even though isiXhosa is transparently written, many participants in our sample were not fluent readers, and had underdeveloped PA. We argue in agreement with Probert and de Vos (2016: 7) and Probert 
(2019: 10) that isiXhosa readers rely on other reading strategies either in addition to phonological recoding, or as a compensation strategy for poor phonological processing and/or poor phonological recoding skills. In this case, the available evidence suggests that the morpheme is used as an additional reading strategy.

Finally, our data support the predictions of the PGST with regard to phonological availability and granularity, and support the inclusion of the morpheme as a grain size used in reading fluency. Our data show that readers had a better awareness of syllables than phonemes, most likely because of the syllable structure of isiXhosa. Furthermore, the awareness of morphemes was a better predictor of reading than PA in this grade 3 sample, suggesting that the morpheme was used as a grain size by these learners.

\section{CONCLUSION}

Our study was the first of its kind to examine the unique contribution of PA, RAN and MA to ORF in isiXhosa, a Southern Bantu language. Only RAN and MA were significant predictors of ORF after controlling for each other and PA in this sample of grade 3 learners. Our results suggest that the role of PA in reading fluency in isiXhosa, and possibly other Southern Bantu languages, may have so far been overestimated because other studies have not controlled for the influence of both MA and RAN. Our results further suggest that isiXhosa grade 3 readers use morphemes as grain sizes, possibly due to the complex morphology of isiXhosa, or possibly as a method to overcome underdeveloped phonological processing skills. Morphemes may be useful linguistic units to target in pedagogical programmes. Our results also support the findings from other languages that RAN is an important cognitive-linguistic skill for reading fluency.

These results have pedagogical implications. Although our study did not find a significant contribution of PA to ORF, the fact that so many learners scored zero on the PA tasks indicates that learners could benefit from a structured phonics programme, which supports efficient phonology-orthography associations, suggested also by Wilsenach (2019: 9). Given the importance of MA for ORF, our results suggest that MA should be explicitly addressed and integrated during class time as well, as suggested by Bowers et al. (2010: 173). There is not yet consensus as to the efficacy of RAN interventions for improving both RAN and reading fluency, so it is unclear what the implication of this finding is for isiXhosa reading pedagogy as yet. Despite this, our data show that RAN has a role to play in reading fluency, at least at grade 3 level. RAN tasks are quick to administer and may be a worthwhile measure to include in future studies. These implications for instruction remain tentative given our cross-sectional research design. Nevertheless, our study indicates that it is important to assess a range of cognitivelinguistic skills to determine their importance for reading fluency. Longitudinal research designs and intervention studies are needed to determine the direction of causality among variables in order to better inform isiXhosa reading pedagogy. 


\footnotetext{
${ }^{1}$ The official Southern Bantu languages offered in the curriculum include: isiZulu, isiXhosa, Siswati, isiNdebele, Sesotho, Sesotho sa Leboa, Setswana, Xitsonga and Tshivenda.

${ }^{2}$ The language term 'Northern Sotho' is used by the authors referred to in this article in their research, so we have used this same term for consistency. However, it is also known by the name of its standardised dialect version 'Sepedi' or its official term, 'Sesotho sa Leboa'.

${ }^{3}$ We use this term throughout as it most commonly occurs in the literature.

${ }^{4}$ Interested readers are directed to Kirby et al. (2010) and Araújo et al. (2015) for more information.

${ }^{5}$ Sesotho sa Leboa is one of the eleven official languages in South Africa. As outlined previously, it is also commonly known as Northern Sotho, or by the name of its standardised dialect, Sepedi.

${ }^{6}$ For more detail on the phonological awareness task development, see Diemer (2016) and Probert (2016).

${ }^{7}$ For more detail about the morphological awareness task development, see Rees (2016).

${ }^{8}$ The average age for the sample of Grade 3 learners was 9 years and 9 months old. Therefore, those learners aged 12 years or older might have repeated an earlier grade or the current grade, or enrolled late in school.
}

\section{REFERENCES}

ACHA, J, I LAKA \& M PEREA. 2010. Reading development in agglutinative languages: evidence from beginning, intermediate, and adult Basque readers. Journal of Experimental Child Psychology, 105:359-375.

ANTHONY, JL, CJ LONIGAN, K DRISCOLL, BM PHILLIPS \& SR BURGESS. 2003. Phonological sensitivity: A quasi-parallel progression of word structure units and cognitive operations. Reading Research Quarterly, 38(4):470-487.

ARAÚJO, S, A REIS, KM PETERSSON \& L FAÍSCA. 2015. Rapid automatized naming and reading performance: A meta-analysis. Journal of Educational Psychology, 107(3):868883.

BERTRAM, R, M LAINE \& M VIRKKALA. 2000. The role of derivational morphology in vocabulary acquisition: Get by with a little help from my morpheme friends. Scandinavian Journal of Psychology, 41(4):287-296.

BOWERS, PN, JR KIRBY \& SH DEACON. 2010. The effects of morphological instruction on literacy skills: A systematic review of the literature. Review of Educational Research, 80(2):144-179.

CARAVOLAS, M, A LERVÅG, S DEFIOR, GS MÁlKOVÁ \& C HULME. 2013. Different patterns, but equivalent predictors, of growth in reading in consistent and inconsistent orthographies. Psychological Science, 24(8):1398-1407.

CARLISLE, JF. 2003. Morphology matters in learning to read: A commentary. Reading Psychology, 24(3-4):291-322.

COMPTON, DL, RK OLSON, JC DEFRIES \& BF PENNINGTON. 2002. Comparing the relationships among two different versions of alphanumeric rapid automatized naming and word level reading skills. Scientific Studies of Reading, 6(4):343-368.

D'ALESSIO, MJ, V JAICHENCO \& M WILSON. 2018. The role of morphology in word naming in Spanish-speaking children. Applied Linguistics, 39(5):1-29.

DANIELS, PT \& DL SHARE. 2018. Writing system variation and its consequences for reading and dyslexia. Scientific Studies of Reading, 22(1):101-116. 
DE JONG, PF \& LO VRIELINK. 2004. Rapid automatic naming: Easy to measure, hard to improve (quickly). Annals of Dyslexia, 54(1):65-88.

DE VOS, M, K VAN DER MERWE \& C VAN DER MESCHT. 2015. A linguistic research programme for reading in African languages to underpin CAPS. Journal for Language Teaching, 48(2):148-177.

DEACON, SH, JR KIRBY \& M CASSELMAN-BELL. 2009. How robust is the contribution of morphological awareness to general spelling outcomes? Reading Psychology, 30(4):301318.

DESROCHERS, A, G MANOLITSIS, P GAUDREAU \& G GEORGIOU. 2018. Early contribution of morphological awareness to literacy skills across languages varying in orthographic consistency. Reading and Writing, 31(8):1695-1719.

DIEMER, M. 2016. The contributions of phonological awareness and naming speed to the reading fluency, accuracy, comprehension and spelling of grade 3 isiXhosa readers. Unpublished master's thesis, Rhodes University, Makhanda.

DIEMER, M, K VAN DER MERWE \& M DE VOS. 2015. The development of phonological awareness literacy measures for isiXhosa. Southern African Linguistics and Applied Language Studies, 33(3):325-341.

DOKE, C. 1954. The Southern Bantu languages. London: Oxford University Press.

DU PLESSIS, JA. 1997. Stellenbosch communication in African languages 6: Imofoloji yeelwimi zaseAfrika [morphology of the African languages]. Stellenbosch, South Africa: Stellenbosch University.

DUBECK, MM \& A GOVE. 2015. The early grade reading assessment (EGRA): Its theoretical foundation, purpose, and limitations. International Journal of Educational Development, 40(January):315-322.

DURGUNOĞLU, A. 2006. Learning to read in Turkish. Developmental Science, 9(5):437-439.

FUGATE, MH. 1997. Letter training and its effect on the development of beginning reading skills. School Psychology Quarterly, 12(2):170-192.

GEORGIOU, GK, R PARRILA \& TC PAPADOPOULOS. 2016a. The anatomy of the RANreading relationship. Reading and Writing, 29(9):1793-1815.

GEORGIOU, GK, M ARO, C LIAO \& R PARRILA. 2016b. Modeling the relationship between rapid automatized naming and literacy skills across languages varying in orthographic consistency. Journal of Experimental Child Psychology, 143 (March):48-64.

GEORGIOU, GK, W WEI, T INOUE, T \& C DENG. 2020. Are the relations of rapid automatized naming with reading and mathematics fluency bidirectional? Evidence from a 5-year longitudinal study with Chinese children. Journal of Educational Psychology, advance online publication.

GOSWAMI, U \& P BRYANT. 2016. Phonological skills and learning to read. Oxon: Routledge.

GOSWAMI, U \& JC ZIEGLER. 2006. Fluency, phonology and morphology: A response to the commentaries on becoming literate in different languages. Developmental Science, 9(5):451-453.

GXILISHE, S, MR SMOUSE, T XHALISA\& J DE VILLIERS. 2009. Children's insensitivity to information from the target of agreement: The case of Xhosa. In J Crawford, K Otaki \& M Takahashi (Eds), Generative approaches to language acquisition North America (GALANA). Somerville, MA: Cascadilla Proceedings Project. 46-53. 
HOWIE, S, C COMBRINCK, M TSHELE, K ROUX, NM PALANE \& G MOKOENA. 2017. Progress in international reading literacy study 2016: South African children's reading literacy achievement. Pretoria: Centre for Evaluation and Assessment.

HOWIE, S, S VAN STADEN, M TSHELE, C DOWSE \& L ZIMMERMAN. 2012. PIRLS 2011 summary report: South African children's reading literacy achievement. Pretoria: Centre for Evaluation and Assessment.

HOWIE, S, E VENTER, S VAN STADEN, L ZIMMERMAN, C LONG, C DU TOIT, V SCHERMAN \& E ARCHER. 2008. PIRLS 2006 summary report: South African children's reading achievement. Pretoria: Centre for Evaluation and Assessment.

HULME, C \& MJ SNOWLING. 2015. Learning to read: What we know and what we need to understand better. Child Development Perspectives, 1(7):1-5.

IBM CORP. 2017. IBM SPSS Statistics for Windows, Version 25.0. Armonk, NY: IBM Corp.

INOUE, T, GK GEORGIOU, N MUROYA, H MAEKAWA \& R PARRILA. 2017. Cognitive predictors of literacy acquisition in syllabic Hiragana and morphographic Kanji. Reading and Writing, 30(6):1335-1360.

KIM, YG \& B PIPER. 2019a. Cross-language transfer of reading skills: An empirical investigation of bidirectionality and the influence of instructional environments. Reading and Writing, 32(4):839-871.

KIM, YG \& B PIPER. 2019b. Component skills of reading and their structural relations: Evidence from three sub-Saharan African languages with transparent orthographies. Journal of Research in Reading, 42(2):326-348.

KIRBY, JR, SH DEACON, PN BOWERS, L IZENBERG, L WADE-WOOLLEY \& $R$ PARRILA. 2012. Children's morphological awareness and reading ability. Reading and Writing, 25(2):389-410.

KIRBY, JR, GK GEORGIOU, R MARTINUSSEN \& R PARRILA. 2010. Naming speed and reading: From prediction to instruction. Reading Research Quarterly, 45(3):341-362.

KOTZE, J, B FLEISCH \& S TAYLOR. 2019. Alternative forms of early grade instructional coaching: Emerging evidence from field experiments in South Africa. International Journal of Educational Development, 66(April):203-213.

KUO, LJ \& R ANDERSON. 2006. Morphological awareness and learning to read: A cross language perspective. Educational Psychology, 41(3):161-180.

LAND, S. 2015. Skilled reading in isiZulu: What can we learn from it? Journal of Education, 63:57-88.

LAND, S. 2016. Automaticity in reading in isiZulu. Reading and Writing: Journal of the Reading Association of South Africa, 7(1):1-13.

LANDERL, K, H FREUDENTHALER, M HEENE, P DE JONG, A DESROCHERS, G MANOLITSIS, R PARRILA \& GK GEORGIOU. 2019. Phonological awareness and rapid automatized naming as longitudinal predictors of reading in five alphabetic orthographies with varying degrees of consistency. Scientific Studies of Reading, 23(3):220-234.

LUO, X, R KONG, L LIU, J WANG, H GU, F HOU, \& R SONG. 2018. Development of orthographic awareness, morphological awareness and rapid automatized naming of elementary-level students in china: A longitudinal analysis from grades 1 to 4 . Current Medical Science, 38(2):336-341.

MAKAURE, ZP. 2016. Phonological processing and reading development in Northern SothoEnglish bilingual children. Unpublished master's thesis, University of South Africa, Pretoria.

Per Linguam 2020 36(1):90-111

http://dx.doi.org/10.5785/36-1-878 
MALDA, M, C NEL \& FJR VAN DE VIJVER. 2014. The road to reading for South African learners: The role of orthographic depth. Learning and Individual Differences, 30:34-45.

MANOLITSIS, G, I GRIGORAKIS \& GK GEORGIOU. 2017. The longitudinal contribution of early morphological awareness skills to reading fluency and comprehension in Greek. Frontiers in Psychology, 8(October):1793.

MANOLITSIS, G, GK GEORGIOU, T INOUE \& R PARRILA. 2019. Are morphological awareness and literacy skills reciprocally related? Evidence from a cross-linguistic study. Journal of Educational Psychology, 111(8):1362-1381.

MCBRIDE-CHANG, C, T TARDIF, JR CHO, H SHU, P FLETCHER, S STOKES, A WONG \& K LEUNG. 2008. What's in a word? Morphological awareness and vocabulary knowledge in three languages. Applied Psycholinguistics, 29(3):437-462.

MCBRIDE-CHANG, C, RK WAGNER, A MUSE, BWY CHOW \& H SHU. 2005. The role of morphological awareness in children's vocabulary acquisition in English. Applied Psycholinguistics, 26(3):415-435.

MOLL, K, F RAMUS, J BARTLING, J BRUDER, S KUNZE, N NEUHOFF, S STREIFTAU, H LYYTINEN, PHT LEPPÄNEN, K LOHVANSUU, D TÓTH, F HONBOLYGÓ, V CSÉPE, C BOGLIOTTI, S IANNUZZI, J DÉMONET, E LONGERAS, S VALDOIS, F GEORGE, I SOARES-BOUCAUD, LE HEUZEY, M BILLARD, C O'DONOVAN, M HILL, G WILLIAMS, J BRANDEIS, D MAURER, U SCHULZ, ES VAN DER MARK, B MÜLLER-MYHSOK, G SCHULTE-KÖRNE \& K LANDERL. 2014. Cognitive mechanisms underlying reading and spelling development in five European orthographies. Learning and Instruction, 29:65-77.

NAKAMURA, PR, RM JOSHI \& XR JI. 2018. Investigating the asymmetrical roles of syllabic and phonemic awareness in akshara processing. Journal of Learning Disabilities, 51(5):499-506.

NORTON, ES, \& M WOLF. 2012. Rapid automatized naming (RAN) and reading fluency: Implications for understanding and treatment of reading disabilities. Annual Review of Psychology, 63:427-452.

NUNES, T, P BRYANT \& M BINDMAN. 2006. The effects of learning to spell on children's awareness of morphology. Reading and Writing, 19(7):767-787.

NURSE, D \& G PHILIPPSON. 2003. Introduction. In D Nurse \& G Philippson (Eds.), The Bantu Languages. London: Routledge.

PIKE, K. 2011. Morphological awareness dynamic assessment task in third grade children: a feasibility study. Unpublished undergraduate honours thesis, Utah State University, Utah.

PRETORIUS, EJN \& SPAULL. 2016. Exploring relationships between oral reading fluency and reading comprehension amongst English second language readers in South Africa. Reading and Writing, 29:1449-1471.

PROBERT, TN \& M DE VOS. 2016. Word recognition strategies amongst isiXhosa/ English bilingual learners: The interaction of orthography and language of learning and teaching. Reading and Writing: Journal of the Reading Association of South Africa, 7(1):1-10.

PROBERT, TN. 2016. A comparative study of syllables and morphemes as literacy processing units in word recognition: IsiXhosa and Setswana. Unpublished master's thesis, Rhodes University, Makhanda.

PROBERT, TN. 2019. A comparison of the early reading strategies of isiXhosa and Setswana first language learners. South African Journal of Childhood Education, 9(1):a643. 
REED, DK. 2008. A synthesis of morphology interventions and effects on reading outcomes for students in grades K - 12. Learning Disabilities Research and Practice, 23(1):36-49.

REES, SA. 2016. Morphological awareness in readers of IsiXhosa. Unpublished master's thesis, Rhodes University, Makhanda.

REPUBLIC OF SOUTH AFRICA. 1996. South Africa Schools Act (Act No. 84 of 1996). Pretoria: Government Printing Works.

RUAN, Y, GK GEORGIOU, S SONG, Y LI \& H SHU. 2018. Does writing system influence the associations between phonological awareness, morphological awareness, and reading? A meta-analysis. Journal of Educational Psychology, 110(2):180-202.

SAIEGH-HADDAD, E \& E GEVA. 2007. Morphological awareness, phonological awareness and reading in English-Arabic bilingual children. Reading and Writing, 21:481-504.

SAUL, ZW. 2013. The significance of accuracy in the orthographical development of isiXhosa in a post-democratic South Africa. Unpublished doctoral thesis, University of Fort Hare, Alice.

SCHAEFER, M \& J KOTZE. 2019. Early reading skills related to Grade 1 English second language literacy in rural South African schools. South African Journal of Childhood Education, 9(1):a644.

SCHROEDER, L. 2013. Teaching and assessing independent reading skills in multilingual African countries: Not as simple as ABC. In C Benson \& K Kosonen (Eds), Language issues in comparative education: Inclusive teaching and learning in non-dominant languages and cultures. Rotterdam: Sense Publishers. 243-264.

SHARE, D. 2008. On the Anglocentricities of current reading research and practice: The perils of overreliance on an "outlier" orthography. Psychological Bulletin, 134(4):584-614.

SHARE, DL \& PT DANIELS. 2016. Ashkaras, alphasyllabaries, abugidas, alphabets and orthographic depth: Reflections on Rimzhim, Katz and Fowler (2014). Writing Systems Research, 8(1):17-31.

SHIN, J, M SAILORS, N MCCLUNG, PD PEARSON, JV HOFFMAN \& M CHILIMANJIRA. 2015. The case of Chichewa and English in Malawi: The impact of first language reading and writing on learning English as a second language. Bilingual Research Journal, 38:255274.

SPAULL, N, E PRETORIUS \& N MOHOHLWANE 2020. Investigating the Comprehension Iceberg: Developing empirical benchmarks for early grade reading in agglutinating African languages. South African Journal of Childhood Education, 10(1):a773.

STATISTICS SOUTH AFRICA. 2012. Census 2011 in brief. Pretoria: Statistics South Africa.

SUGGATE, SP. 2016. A meta-analysis of the long-term effects of phonemic awareness, phonics, fluency, and reading comprehension interventions. Journal of Learning Disabilities, 49(1):77-96.

SWANSON, HL, G TRAININ, DM NECOECHEA \& DD HAMMILL. 2003. Rapid naming, phonological awareness, and reading: A meta-analysis of the correlation evidence. Review of Educational Research, 73(4):407-440.

TALJARD, E \& SE BOSCH. 2006. A comparison of approaches to word class tagging: Disjunctively vs/ conjunctively written Bantu languages. Nordic Journal of African Studies, 15(4):428-442.

TIBI, S \& JR KIRBY. 2018. Investigating phonological awareness and naming speed as predictors of reading in Arabic. Scientific Studies of Reading, 22(1):70-84. 
TRUDELL, B \& L SCHROEDER. 2007. Reading methodologies for African languages: Avoiding linguistic and pedagogical imperialism. Language, Culture and Curriculum, 20(3):165-180.

VAESSEN, A, S BERTRAND, D TÓTH, V CSÉPE, L FAÍSCA, A REIS \& L BLOMERT. 2010. Cognitive development of fluent word reading does not qualitatively differ between transparent and opaque orthographies. Journal of Educational Psychology, 102(4):827-842.

VAN DER MERWE, A \& M LE ROUX. 2014. Idiosyncratic sound systems of the Bantu languages: Research and clinical implications for speech-language pathologists and audiologists. South African Journal of Communication Disorders, 61(11):1-8.

VANDER STAPPEN, C \& M VAN REYBROECK. 2018. Phonological awareness and rapid automatized naming are independent phonological competencies with specific impacts on word reading and spelling: An intervention study. Frontiers in Psychology, 8:1-16.

VEII, K \& J EVERATT. 2005. Predictors of reading among Herero-English bilingual Namibian school children. Bilingualism, 8(3):239.

VERHOEVEN, L \& C PERFETTI. 2017. Introduction: Operating principles in learning to read. In L Verhoeven \& C Perfetti C (Eds), Learning to read across languages and writing systems. Cambridge: Cambridge University Press. 1-25.

WILSENACH, C. 2013. Phonological skills as predictor of reading success: An investigation of emergent bilingual Northern Sotho/English learners. Per Linguam, 29(2):17-32.

WILSENACH, C. 2019. The role of phonological awareness in Northern Sotho reading understanding the contribution of phonemes and syllables in Grade 3 reading attainment. South African Journal of Childhood Education, 9(1):a647.

WOLF, M. \& PG BOWERS. 1999. The double-deficit hypothesis for the developmental dyslexias. Journal of Educational Psychology, 91(3):415-438.

WOLFF, U. 2014. RAN as a predictor of reading skills, and vice versa: Results from a randomised reading intervention. Annals of Dyslexia, 64(2):151-165.

WOLTER, JA, A WOOD \& KW D'ZATKO. 2009. The influence of morphological awareness on the literacy development of first-grade children. Language, Speech and Hearing Service in Schools, 40(3):286-298.

YAN, G, H TIAN, X BAI \& K RAYNER. 2006. The effect of word and character frequency on the eye movements of Chinese readers. British Journal of Psychology, 97(2):259-268.

ZHANG, D \& K KODA. 2012. Contribution of morphological awareness and lexical inferencing ability to L2 vocabulary knowledge and reading comprehension among advanced EFL learners: Testing direct and indirect effects. Reading and Writing, 25(5):1195-1216.

ZHANG, D \& K KODA. 2013. Morphological awareness and reading comprehension in a foreign language: A study of young Chinese EFL learners. System, 41(4):901-913.

ZIEGLER, JC, D BERTRAND, D TÓTH, D V CSÉPE, A REIS, AL FAÍSCA, N SAINE, H LYYTINEN, A VAESSEN \& L BLOMERT. 2010. Orthographic depth and its impact on universal predictors of reading: A cross language investigation. Psychological Science, 21(4):551-559.

ZIEGLER, JC \& U GOSWAMI. 2005. Reading acquisition, developmental dyslexia, and skilled reading across languages: A psycholinguistic grain size theory. Psychological bulletin, 131(1):3-29.

ZIEGLER, JC, C PERRY, AM JACOBS \& M BRAUN. 2001. Identical words are read differently in different language. Psychological Science, 12(5):379-384. 


\section{DISCLAIMER}

The views expressed in this submitted article are our own and not an official position of our institutions or funders.

\section{ACKNOWLEDGEMENTS}

The original research studies were conceptualised and conducted as part of the postgraduate research of all authors. The data from the postgraduate research were re-analysed for this paper at our current institutions. The postgraduate research was funded by the Sandisa Imbewu Literacy Project (for all three authors), Rhodes University (through Rhodes University Prestigious scholarship awarded to M Schaefer and T Probert), and the Mellon Foundation Scholarship (awarded to M Schaefer).

Prof Mark de Vos, Dr Will Bennet and Ms Kristin van der Merwe are acknowledged as (co)supervisors on the original Masters projects at Rhodes University. Prof. Carien Wilsenach of the University of South Africa (UNISA) is acknowledged for her extensive feedback on an earlier draft of the paper undertaken during the UNISA College of Human Sciences Mentorship Programme 2018.

\section{BIOGRAPHICAL NOTES}

Maxine Schaefer is a Lecturer and PhD candidate in the Linguistics Department at UNISA. Her research focuses on cross-linguistic transfer and the relationship between cognitive-linguistic skills, primarily phonological processing skills, and literacy development in English and the Southern Bantu languages in South Africa. https://orcid.org/0000-0002- 5455-2762

Tracy Probert is a Lecturer in the Department of Linguistics and Applied Language Studies at Rhodes University. Her primary research interest involves the relationship between cognitivelinguistic skills and literacy in the Southern Bantu languages and English. Her additional research interest includes that of multilingual practices in the classroom. https://orcid.org/0000-0002$\underline{9897-3630}$

Siân Rees is a PhD candidate in the Department of Linguistics and Applied Language Studies at Rhodes University and a Materials Developer at Molteno Institute for Language and Literacy. She uses her research on the formal aspects of Bantu languages to develop literacy resources for various languages. https://orcid.org/0000-0002- 5460-469X. 